07

\title{
Полевой транзистор миллиметрового диапазона длин волн на основе псевдоморфной гетероструктуры с дополнительными потенциальными барьерами
}

\author{
(C) С.А. Богданов ${ }^{1}$, А.К. Бакаров ${ }^{2}$, К.С. Журавлев ${ }^{2}$, В.Г. Лапин ${ }^{1}$, В.М. Лукашин ${ }^{1}$, А.Б. Пашковский 1 ฯ, \\ И.A. Рогачёв ${ }^{1}$, E.B. Терёшкин ${ }^{1}$, С.В. Щербаков ${ }^{1}$ \\ ${ }^{1} \mathrm{AO}$ „НПП „Исток“ им Шокина“, Фрязино, Московская обл., Россия \\ ${ }^{2}$ Институт физики полупроводников им. А.В. Ржанова СО РАН, Новосибирск, Россия \\ TE-mail: solidstate10@mail.ru
}

Поступило в Редакцию 2 декабря 2020 г.

В окончательной редакции 29 декабря 2020 r.

Принято к публикации 29 декабря 2020г.

\begin{abstract}
Представлены результаты исследования полевых транзисторов миллиметрового диапазона длин волн с $T$-образным затвором длиной $0.14 \mu \mathrm{m}$ на псевдоморфных гетероструктурах $\mathrm{Al}_{0.3} \mathrm{Ga}_{0.7} \mathrm{As}-\mathrm{In}_{0.22} \mathrm{Ga}_{0.78} \mathrm{As}-\mathrm{Al}_{0.3} \mathrm{Ga}_{0.7} \mathrm{As}$ с дополнительными потенциальными барьерами на основе двустороннего донорно-акцепторного легирования канала. На частоте $40 \mathrm{GHz}$ в широком диапазоне напряжений на затворе достигнута величина максимально стабильного коэффициента усиления более $15 \mathrm{~dB}$. Максимальная частота генерации прибора составляет около $250 \mathrm{GHz}$, удельная плотность тока при открытом канале - около $0.7 \mathrm{~A} / \mathrm{mm}$, пробивное напряжение затвор-сток в зависимости от исполнения составляет $22-31 \mathrm{~V}$.
\end{abstract}

Ключевые слова: дополнительные потенциальные барьеры, полевой транзистор, коэффициент усиления.

DOI: 10.21883/PJTF.2021.07.50802.18640

В настоящее время активное продвижение мощных полупроводниковых приборов в миллиметровый диапазон длин волн связано в основном с совершенствованием эпитаксиальных технологий нитрида галлия. Полевые транзисторы на основе гетероструктур AlGaN-GaN демонстрируют крайне впечатляющие характеристики $[1,2]$ и продвинулись почти до терагерцевого диапазона [3]. Более высокие частоты заняты приборами с узкозонными каналами, сформированными в основном на InP-подложках $[4,5]$. В то же время по высокочастотным свойствам GaN заметно уступает GaAs [6,7]. При этом работы по совершенствованию транзисторов на основе арсенид-галлиевых псевдоморфных гетероструктур практически остановлены. Бурный прогресс в продвижении нитрид-галлиевых приборов, возможно, связан не только с достоинствами эпитаксиальных структур на основе нитрида галлия, но и с огромным объемом затрачиваемых на их развитие средств, а также резко выросшим за последние годы уровнем полупроводниковых технологий. В то же время исследования в области донорно-акцепторного легирования [8] позволили увеличить выходную мощность арсенид-галлиевых транзисторов на основе псевдоморфных гетероструктур. Кроме того, по оценкам [9-11] имеется возможность существенно продвинуться вверх по частотному диапазону.

В настоящей работе приведены первые результаты исследования арсенид-галлиевых полевых транзисторов миллиметрового диапазона длин волн на основе псевдоморфных гетероструктур с донорно-акцепторным легированием (DA-DpHEMT), которые позволяют сделать вывод о больших перспективах этого направления.
Основные параметры слоев гетероструктуры с $\mathrm{In}_{0.22} \mathrm{Ga}_{0.78} \mathrm{As}$-каналом на подложке $\mathrm{GaAs}(100 \mu \mathrm{m})$, a также результаты измерений в ней поверхностной плотности и подвижности электронов приведены в таблице. Следует отметить, что данная структура имеет рекордное среди транзисторных структур этого типа значение поверхностной проводимости канала $\left(\sigma=e \mu n_{s} \approx 4.4 \mathrm{mS}\right)$. На ее основе были изготовлены транзисторы как с различным количеством, так и с различной шириной пальцев затвора (от 50 до $150 \mu \mathrm{m}$ ). Измеренная длина $T$-образного затвора составила около $0.14 \mu \mathrm{m}$. Пробивное напряжение затвор-сток в зависимости от расстояния затвор-сток (рис. 1) изменялось в диапазоне $22-31 \mathrm{~V}$, удельная плотность тока при открытом затворе составляла около $0.7 \mathrm{~A} / \mathrm{mm}$, что по элементарным оценкам соответствует удельной плотности мощности $1.5-2 \mathrm{~W} / \mathrm{mm}$.

Возможность улучшения частотных характеристик полевых транзисторов за счет использования донорно-акцепторного легирования была исследована на мощных DA-DpHEMT с затвором длиной $0.3 \mu \mathrm{m}$ [9]. Было показано, что донорно-акцепторное легирование увеличивает коэффициент усиления такого прибора на $3-4 \mathrm{~dB}$, а при идеальном согласовании на частоте $40 \mathrm{GHz}$ малосигнальный коэффициент усиления достигает $5 \mathrm{~dB}$. Из простейших оценок, основанных на пропорциональности коэффициента усиления транзистора квадрату его граничной частоты усиления по току $f_{t}$, следует, что уменьшение длины затвора с 0.3 до $0.14 \mu \mathrm{m} \mathrm{c} \mathrm{учетом}$ краевых эффектов должно приводить к увеличению $f_{t}$ примерно в 2 раза, что соответствует росту коэффициен- 
Гетероструктура DA-DpHEMT: состав слоев, уровень легирования, подвижность и поверхностная плотность электронов

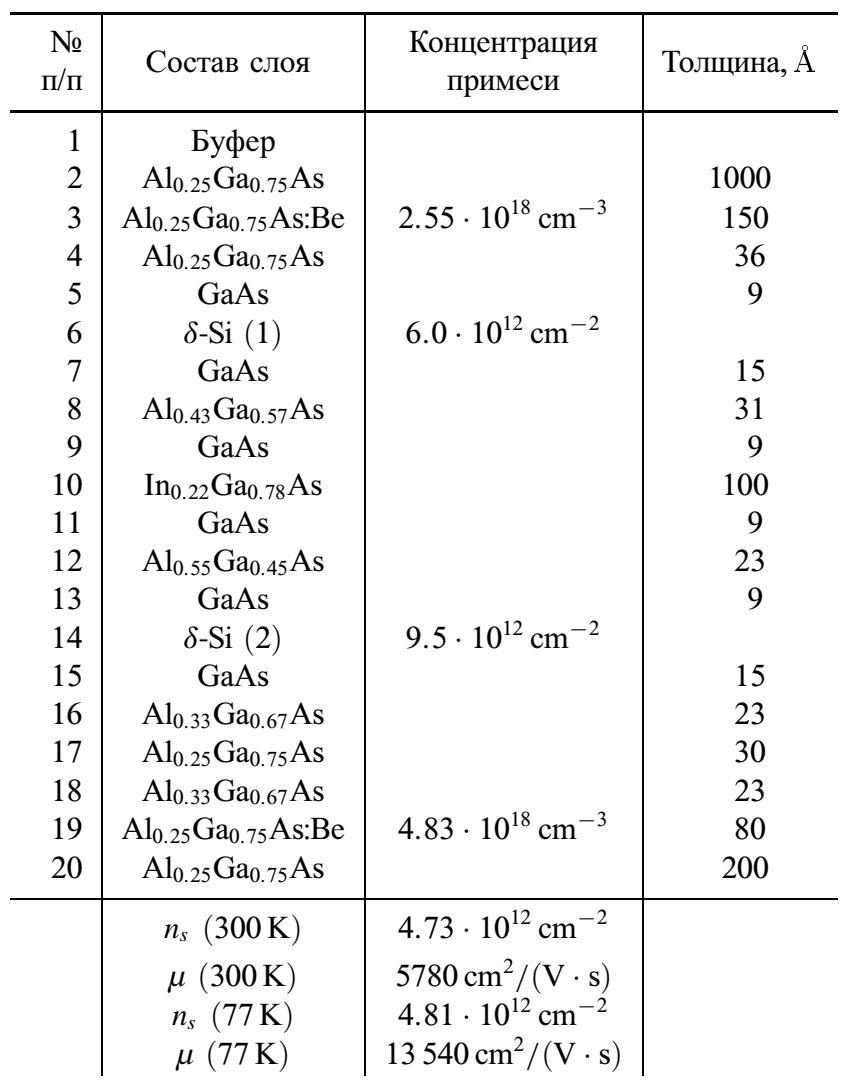

та усиления на $6 \mathrm{~dB}$. С учетом того, что конструкция транзистора в [9] была рассчитана на сантиметровый диапазон длин волн, длина его затвора была измерена с некоторой погрешностью, а также того, что новая гетероструктура имеет очень высокую проводимость, от разрабатываемого на основе новой гетероструктуры прибора на частоте $40 \mathrm{GHz}$ по предварительным оценкам ожидалось получить коэффициент усиления $11-13 \mathrm{~dB}$. Однако СВЧ-измерения показали существенно превышающие эти оценки результаты.

На рис. 1 приведены зависимости максимально стабильного коэффициента усиления транзистора (MSG), рассчитанного по измеренным $S$-параметрам, от расстояния затвор-сток, а на рис. 2 - от напряжения на затворе при различных расстояниях затвор-сток в конфигурации „транзистор с четырьмя одиночными секциями затвора“". Видно, что на частоте $40 \mathrm{GHz}$ в широком диапазоне напряжений на затворе для транзисторов с шириной единичного пальца $50 \mu \mathrm{m}$ коэффициент усиления заметно превосходит величину $15 \mathrm{~dB}$ и достигает в максимуме почти $18 \mathrm{~dB}$, а максимальная величина усиления при других ширинах затворного пальца превосходит $20 \mathrm{~dB}$. При этом максимальная частота генерации для расстояний затвор-сток, соответствующих наибольшей равномерности коэффициента усиления, составляет около $250 \mathrm{GHz}$ при максимальной частоте усиления по току около $45 \mathrm{GHz}$ (рис. 3). Как отмечалось ранее, при длинах затвора 20-35 nm [1-5] приборы на основе GaN и на InP-подложках с узконным каналом демонстрируют гораздо более впечатляющие характеристики, однако перспективность тех или других типов структур следует оценивать при близких длинах затворов, так как простые аппроксимации могут приводить к значительным погрешностям. В свою очередь при близких длинах затворов DA-DpHEMT по коэффициенту усиления и предельным частотам находится на уровне транзисторов на InP-подложках с узкозонным каналом и существенно превосходит GaN-приборы, уступая последним в удель-

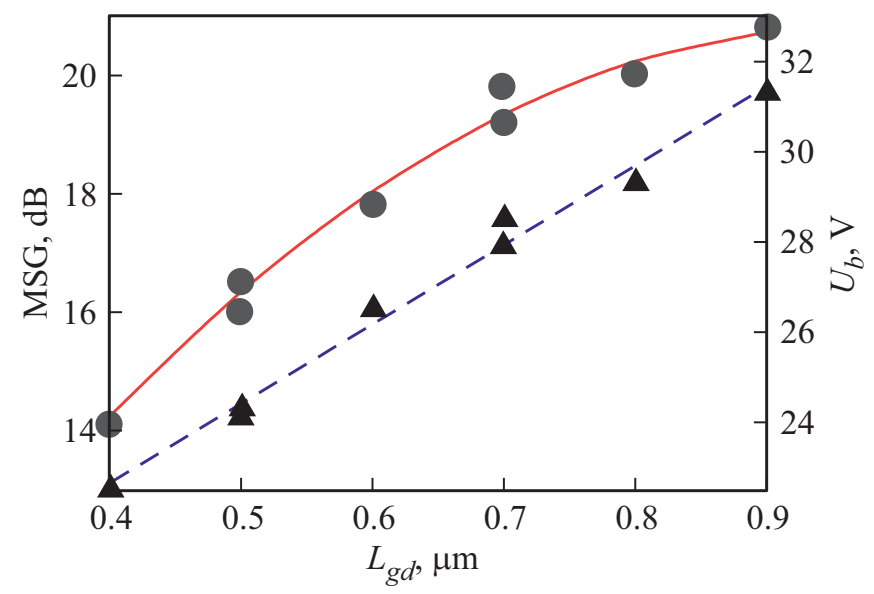

Рис. 1. Зависимость от расстояния затвор-сток максимально стабильного коэффициента усиления (MSG) (кружки эксперимент, сплошная линия - аппроксимация на частоте $40 \mathrm{GHz}$ ) и пробивного напряжения транзистора $U_{b}$ (треугольники - эксперимент, штриховая линия - аппроксимация). Напряжение исток-сток 4 V. Ширина затвора не фиксирована, для заданного расстояния затвор-сток выбирался лучший результат.

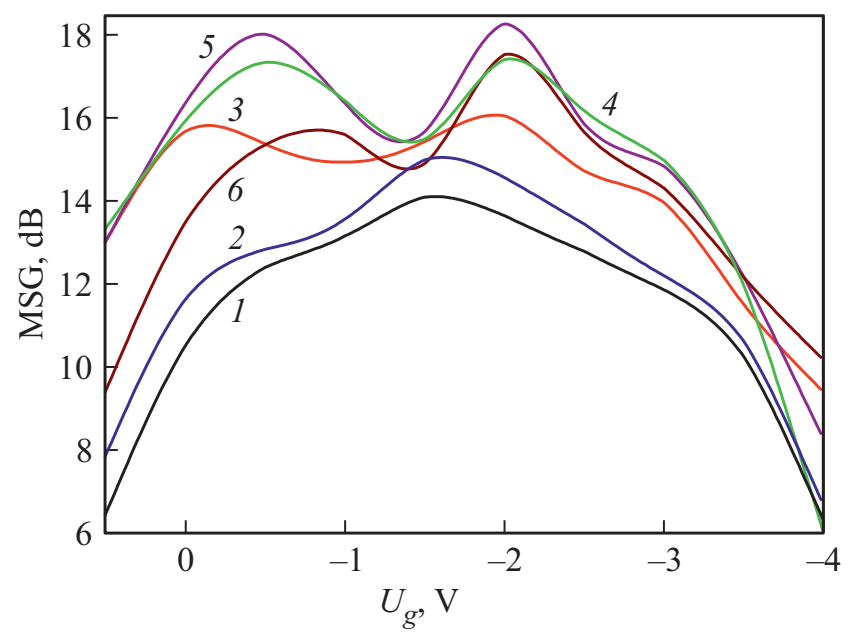

Рис. 2. Зависимость максимально стабильного коэффициента усиления (MSG) на частоте $40 \mathrm{GHz}$ от напряжения на затворе транзистора. Напряжение исток-сток $4 \mathrm{~V}$. Ширина затвора $200 \mu \mathrm{m}$, ширина единичного пальца затвора $50 \mu \mathrm{m}$. Расстояние затвор-сток, $\mu \mathrm{m}: 1-0.4,2-0.5,3-0.6,4-0.7,5-0.8$, $6-0.9$. 


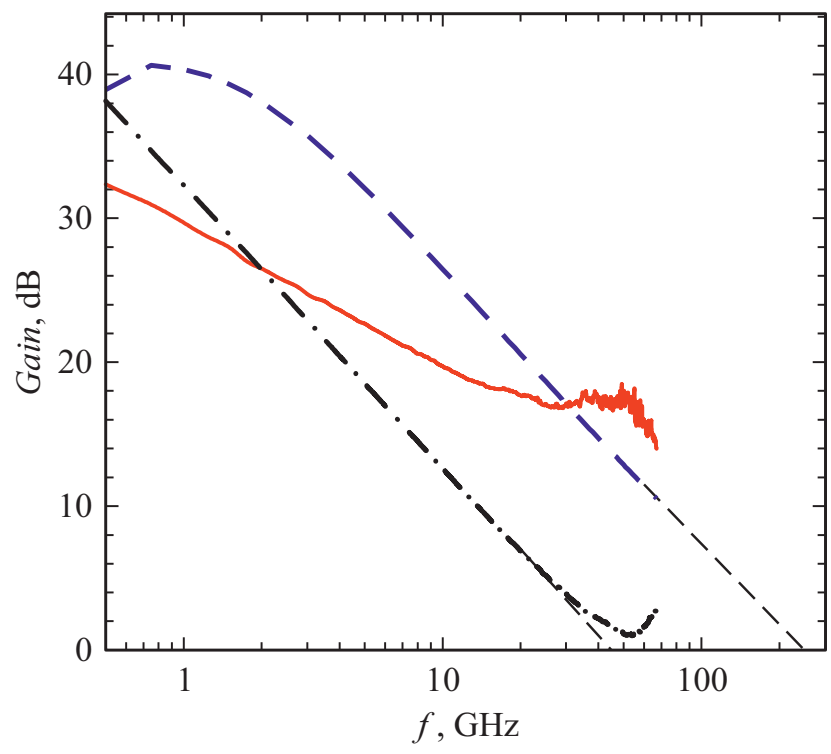

Рис. 3. Зависимости коэффициентов усиления транзистора от частоты. Штрихпунктирная линия - $\left|h_{21}\right|^{2}$, сплошная - MSG, штриховая - Unilateral gain (нелинейная модель, расчет). Напряжение исток-сток 4 V. Ширина затвора $200 \mu \mathrm{m}$, ширина единичного пальца затвора $50 \mu \mathrm{m}$. Расстояние затвор-сток $0.7 \mu \mathrm{m}$.

ной мощности. Таким образом, с учетом максимальных величин плотности тока стока и пробивных напряжений затвор-сток полученные результаты позволяют говорить о DA-DpHEMT как об одном из лучших арсенидгаллиевых приборов в миллиметровом диапазоне длин волн при данной норме размерной обработки (длине затвора).

Использованная гетероструктура $\mathrm{Al}_{0.3} \mathrm{Ga}_{0.7} \mathrm{As}-$ $\mathrm{In}_{0.22} \mathrm{Ga}_{0.78} \mathrm{As}-\mathrm{Al}_{0.3} \mathrm{Ga}_{0.7} \mathrm{As}$ с донорно-акцепторным легированием хотя и демонстрирует очень высокие характеристики по слабополевой проводимости, но, возможно, является далеко не самой оптимальной. Близкую, а возможно, и несколько бо́льшую удельную плотность тока при примерно таких же пробивных напряжениях, но заметно большем коэффициенте усиления [10,12] можно получить на исследованных в [13] гетероструктурах $\mathrm{In}_{0.2} \mathrm{Al}_{0.8} \mathrm{As}-\mathrm{In}_{0.2} \mathrm{Ga}_{0.8} \mathrm{As}-\mathrm{In}_{0.2} \mathrm{Al}_{0.8} \mathrm{As}$, имеющих такую же ширину запрещенной зоны в слое канала. Кроме того, согласно проведенным в [12] оценкам, продвинуться по частотному диапазону в терагерцевую область можно, используя гетероструктуры $\operatorname{In}_{0.52} \mathrm{Al}_{0.48} \mathrm{As}-\mathrm{In}_{0.53} \mathrm{Ga}_{0.47} \mathrm{As}-$ $\mathrm{In}_{0.52} \mathrm{Al}_{0.48} \mathrm{As}$ с двусторонним относительно слоя $\mathrm{In}_{0.53} \mathrm{Ga}_{0.47} \mathrm{As}$-канала донорно-акцепторным легированием, однако за это придется расплачиваться падением пробивного напряжения из-за меньшей ширины запрещенной зоны $\operatorname{In}_{0.53} \mathrm{Ga}_{0.47} \mathrm{As}$-канала.

Полученные результаты еще раз свидетельствуют о том, что донорно-акцепторное легирование является крайне эффективным способом улучшения транзисторных гетероструктур, а полевые транзисторы на таких структурах по ряду параметров могут составить достой- ную конкуренцию приборам на основе нитрида галлия, особенно в миллиметровом и субмиллиметровом диапазонах длин волн.

\section{Финансирование работы}

Работа выполнена при поддержке Министерства науки и высшего образования, грант № 075-15-2020-797 (13.1902.21.0024).

\section{Конфликт интересов}

Авторы заявляют, что у них нет конфликта интересов.

\section{Список литературы}

[1] H. Wang, F. Wang, S. Li, T.Y. Huang, A.S. Ahmed, N.S. Mannem, J. Lee, E. Garay, D. Munzer, C. Snyder, S. Lee, H.T. Nguyen, M.E.D. Smith, Power amplifiers performance survey 2000-present [Электронный ресурс]. Режим доступа: https:/gems.ece.gatech.edu/PA_survey.html

[2] B. Romanczyk, S.Wienecke, M. Guidry, H. Li, E. Ahmadi, X. Zheng, S. Keller, U.K. Mishra, IEEE Trans. Electron Dev., 65 (1), 45 (2018). DOI: 10.1109/TED.2017.2770087

[3] Y. Tang, K. Shinohara, D. Regan, A. Corrion, D. Brown, J. Wong, A. Schmitz, H. Fung, S. Kim, M. Micovic, IEEE Electron Dev. Lett., 36 (6), 549 (2015). DOI: $10.1109 /$ LED.2015.2421311

[4] V. Camarchia, R. Quaglia, A. Piacibello, D.P. Nguyen, H. Wang, A. Pham, IEEE Trans. Microwave Theory Tech., 68 (7), 199 (2020). DOI: 10.1109/TMTT.2020.2989792

[5] X. Mei, W. Yoshida, M. Lange, J. Lee, J. Zhou, P. Liu, K. Leong, A. Zamora, J. Padilla, S. Sarkozy, R. Lai, W.R. Deal, IEEE Electron Dev. Lett., 36 (4), 327 (2015). DOI: 10.1109/LED.2015.2407193

[6] B.E. Foutz, S.K. O’Leary, M.S. Shur, L.F. Eastman, J. Appl. Phys., 85 (11), 7727 (1999). DOI: 10.1063/1.370577

[7] А.Б. Пашковский, В.М. Лукашин, Я.Б. Мартынов, В.Г. Лапин, А.А. Капралова, И.А. Анисимов, Электронная техника. Сер. 1. СВЧ-техника, № 4 (523), 5 (2014).

[8] В.М. Лукашин, А.Б. Пашковский, К.С. Журавлев, А.И. Торопов, В.Г. Лапин, А.Б. Соколов, Письма в ЖТФ, 38 (17), 84 (2012).

[9] А.А. Борисов, К.С. Журавлев, С.С. Зырин, В.Г. Лапин, В.М. Лукашин, А.А. Маковецкая, В.И. Новоселец, А.Б. Пашковский, А.И. Торопов, Н.Д. Урсуляк, С.В. Щербаков, Письма в ЖТФ, 42 (16), 41 (2016).

[10] А.Б. Пашковский, С.И. Новиков, В.Г. Лапин, В.М. Лукашин, Я.Б. Мартынов, Письма в ЖТФ, 44 (17) 103 (2018). DOI: $10.21883 /$ PJTF.2018.17.46577.17372

[11] Д.Ю. Протасов, Д.В. Гуляев, А.К. Бакаров, А.И. Торопов, Е.В. Ерофеев, К.С. Журавлев, Письма в ЖТФ, 44 (6), 77 (2018). DOI: 10.21883/PJTF.2018.06.45770.17098

[12] А.Б. Пашковский, А.С. Богданов, В.М. Лукашин, С.И. Новиков, Микроэлектроника, 49 (3), 210 (2020). DOI: $10.31857 / \mathrm{S} 0544126920030059$

[13] И.С. Василевский, А.Н. Виниченко, Н.И. Каргин, В сб. Мокеровские чтения. 8-я Меюкуунар. науч.-практ. конф. по физике и технологии наногетероструктурной СВЧ-электроники (НИЯУ МИФИ, М., 2017), с. 28. 